\title{
Verification under the Chemical Weapons Convention. A reflective review*
}

\author{
Ron G. Manley \\ Organisation for the Prohibition of Chemical Weapons, The Hague, Netherlands
}

\begin{abstract}
The verification regime of the Chemical Weapons Convention (CWC) has now been in operation for more than five years. Its two principal components are the declarations to be made by States Parties and the on-site inspections carried out by the Organisation for the Prohibition of Chemical Weapons (OPCW) inspectors to verify these declarations. Its implementation has proved to be a resounding success-more than 1200 on-site inspections have been carried out in over 50 of the Convention's 145 States Parties and many practical lessons have been learned. To ensure the continued success of the verification regime, some problems - particularly in relation to industry declarations, the updating of the approved list of inspection equipment, on-site sampling and analysis, and off-site analysis—need to be resolved.
\end{abstract}

\section{INTRODUCTION}

The CWC [1] came into force on 29 April 1997, and implementation of its complex and sophisticated verification regime began shortly thereafter. Over the succeeding 5 years, declarations have been received from more than 140 States Parties to the Convention and more than 1200 on-site inspections have been carried out in approximately 50 of these States Parties. Whereas implementation of the Convention's verification regime has been a great success, five years of operational experience have yielded a number of valuable lessons.

\section{DECLARATIONS}

A key element of the verification regime of the CWC is the declaration to be submitted by each State Party to the Convention. With the exception of special situations, such as a "Challenge Inspection", onsite inspections - the other key element of the Convention's verification regime-are restricted to the confirmation of the veracity of these declarations. Their quality and completeness is, therefore, of considerable importance. This factor was well understood by the drafters of the Convention, and the text relating to the declaration requirements is both extensive and detailed. The degree of detail contained in the final text, however, has, in itself, generated problems. The declaration requirements are, in some instances, so complex that their correct interpretation requires a considerable knowledge of the subject and specialized training.

In accordance with the Convention, each State Party is required to submit its initial declaration within 30 days of the Convention entering into force for it. The principal declaration requirements are as follows. Each State Party must provide detailed information on any chemical weapons or chemical weapons production facilities that it has on its territory or has had at any time since 1946. It must, to the extent it can, provide information on any chemical weapons that have been abandoned on its terri-

*Lecture presented at the IUPAC Workshop, Impact of Scientific Developments on the Chemical Weapons Convention, Bergen, Norway, 30 June-3 July 2002. Other presentations are published in this issue, pp. 2229-2322. 
tory or that it has abandoned on the territory of another State Party in the period since 1925. Information on how a State Party proposes to destroy any chemical weapons it possesses in accordance with the requirements and timelines set down in the Convention must also be provided.

States Parties must also provide a wide range of information in relation to the chemical industries on their territory that produce-and, in certain instances, process or consume-chemicals that are considered to pose a potential risk to the Convention. These "dual-purpose" chemicals are listed on three schedules of chemicals annexed to the Convention [2]. Chemicals listed on Schedule 1 are very toxic substances, which either have been, or have the potential to be, used as chemical weapons (e.g., the organophosphorus nerve agents and the nitrogen and sulfur mustard gases) and the key precursor chemicals necessary to produce them (e.g., the alkyl phosphonydiflourides, such as methylphosphonyldifluoride) that have little or no legitimate use for peaceful purposes. The chemicals listed on Schedule 2 are toxic chemicals, which have the potential to be used as chemical weapons (e.g., the organophosphorus pesticide Amiton) and key precursors (e.g., dimethyl methylphosponate, thiodiglycol, and arsenic trichloride) that are also produced and used in significant quantities for normal commercial purposes. Chemicals listed on Schedule 3 are toxic chemicals that have been used as chemical weapons (e.g., phosgene and hydrogen cyanide) and precursors (e.g., phosphorus trichloride, trimethyl phosphite, thionyl chloride, and triethanolamine) that are produced for legitimate purposes by the world's commercial chemical industries on a very large scale. Under the Convention, chemicals on Schedule 1 are subjected to the strictest control and those on Schedule 3 to the least. States Parties must also provide information in relation to facilities on their territory which produce more than 200 tonnes of unscheduled discrete organic chemicals (DOCs) per year and more than 30 tonnes of unscheduled DOCs containing the elements sulfur, phosphorus, or fluorine (PSFs) per year.

Each State Party is also required to provide a range of administrative information, such as the name and contact information of its National Authority (the body or person appointed by the State Party to serve as its focal point for the Convention) and its designated points of entry for OPCW inspectors.

In reality, only a few States Parties were able to meet the required timeline for the provision of their initial declaration, and of those that did, almost all subsequently submitted amendments to their initial declaration as further information became available. The Technical Secretariat of the OPCW was, therefore, faced with a very large influx of data of varying quality and completeness. In addition, most of the data received from the States Parties was classified as highly confidential. The absence of an approved, secure computer system meant that, until late in the year 2000, all of this data had to be handled in hard-copy format. And, even though all declaration data is now scanned and stored electronically, its detailed analysis remains difficult due to the lack of a relational database capable of operating at the level of security required by States Parties to protect their information.

The situation was further complicated by the fact that five years of operational experience have shown that, despite the best efforts of the drafters of the Convention, a number of the declaration requirements are still open to interpretation. This is a particular problem with respect to declarations made under Article VI of the Convention that deals with activities not prohibited under the Convention, i.e., "chemical industry declarations". Despite many hours of discussion by the States Parties, consensus on the precise meaning of a number of these problem areas has yet to be achieved. As a result, each State Party continues to place its own interpretation on the declaration requirements in relation to these problem areas. This has greatly complicated the Technical Secretariat's task of assessment and analysis of States Parties declarations and the subsequent planning of inspections. Despite these difficulties, however, a considerable amount of statistical data has been generated, and a large number of inspections have been completed.

\section{INSPECTIONS}

OPCW inspectors are full-time employees of the Organisation. They are recruited from Member States and trained and paid by the Organisation. Each inspector has completed a six-month training course, 
which provides, inter alia, extensive training on the Convention; an introduction to chemical weapons, their production and safe destruction; inspection skills; health and safety issues; and the development of multicultural communication and negotiation skills. They also receive further intensive training in their respective specialist areas. The Organisation has approximately 200 inspectors drawn from 68 Member States. Most are either professional chemical engineers or industrial chemists. The remainder are chemical weapons specialists, analytical chemists, or medical personnel. One of the problems currently facing the Organisation is how best to train new inspectors required to fill the vacancies created by the small number of inspectors who leave each year. Repeating the original intensive, six-month training program for the small numbers of replacement inspectors required each year would be very expensive and, in any case, may not be the optimum way forward. A solution to this question of the training of future inspectors becomes more urgent as each year passes.

All inspections are undertaken in accordance with the general rules and guidance set out in the Convention's Verification Annex. In addition, the Verification Annex contains specific rules and guidance for particular types of inspection, and these must also be applied when the related type of inspection is being undertaken. In the period since entry into force of the Convention, the States Parties have, in the form of Conference decisions, provided additional guidance and further interpretation of some of these rules. The aim of these rules and guidance is to ensure that both the inspected State Party and the inspectors each have a clear understanding of the framework under which the inspection is being carried out and the extent of each side's privileges and responsibilities. In general, the rules provide sufficient flexibility to enable both the State Party and the inspection team to reach agreement on a satisfactory means of completing the inspection. The aim is at all times to maintain a balance between the inspection team's need to fulfill its mandate and the State Party's need to protect matters of national security and confidential business information.

Inspectors may only take equipment from the approved inspection equipment list to an inspection site. Inspected States Parties have the right to satisfy themselves, at the designated point of entry to their territory, that each item of the team's inspection equipment is on the approved list and complies with the approved technical specifications for that particular item. The inspection equipment list was drawn up prior to entry into force of the Convention and, therefore, it is perhaps not surprising that, after five years of operational experience, some items have been found to be more useful than others. The drafters of the Convention again foresaw this problem, and the text requires the Technical Secretariat to take action to update the approved inspection equipment list as and when necessary. Unfortunately, the text does not provide a procedure or mechanism for achieving this task, and to date it has not proved possible to achieve a consensus among the States Parties on the need to update or amend the approved inspection equipment list. This is perhaps one of the more serious problems facing the Technical Secretariat, as, due to this lack of consensus, it is currently unable to take full advantage of developments and changes in technology.

The CWC provides for a number of different types of on-site inspection. Chemical weapons production facilities are subject to routine inspections until they have either been destroyed or converted for use for peaceful purposes. Where approval has been granted, by the States Parties, for facilities to be converted, they remain subject to inspection for at least 10 years after the conversion has been completed. Of the 61 facilities declared by 11 States Parties, all have been inactivated and more than $50 \%$ have already either been completely destroyed or converted for use for peaceful purposes.

The 32 chemical weapons storage facilities, declared by 4 States Parties, are subject to routine inspection until such time as all of the chemical weapons stored at the site have been destroyed. In addition to monitoring the number of chemical weapons stored at each facility, OPCW inspectors are also required to verify the identity of the chemical agents contained in them. One option provided by the Convention for achieving this is for the inspectors to have samples taken from munitions for chemical analysis. For health and safety reasons, however, inspected States Parties will not, normally, permit the sampling of chemical munitions at storage facilities. The alternative option is for the inspectors to tag the munitions of interest for subsequent sampling at the point of their destruction. This latter option, 
however, poses two problems. First, the sampling of a tagged munition, even during its destruction, adds significantly to the cost of destruction. The concerned States Parties, therefore, wish to keep the number of munitions tagged by inspectors to a minimum. Second, it may be several years before the tagged munition is sent for destruction and the required sample taken. One possible solution to this problem is the use of nondestructive analysis (NDA) techniques on the stored chemical munitions. A number of techniques have been explored, including: radiography, using portable X-ray equipment; ultrasonic pulse echo; acoustic resonance spectroscopy (ARS); neutron-induced prompt photon spectroscopy (NIPPS); and the measurement of hydrogen concentration, using neutron activation (HCM). While each of these techniques has its particular advantages and disadvantages, none of them provides a fully satisfactory solution to the problem. A means of increasing the inspector's confidence with regard to the identity of the contents of the stored chemical munitions has, therefore, yet to be found.

OPCW inspectors are also required to maintain a continuous on-site presence at chemical weapons destruction facilities during any period in which chemical weapons are being destroyed. This has proved to be an extremely resource intensive activity and one which currently absorbs more than $65 \%$ of the OPCW inspector's resources. The pace of chemical weapons destruction is expected to increase significantly over the next 3 to 4 years as those States Parties that possess chemical weapons strive to meet the 10-year deadline for their destruction. The problem in relation to inspector resources will continue to grow unless a more efficient method of verifying the destruction of these munitions can be developed and approved for use.

The inspection regime for facilities declared under Article VI, chemical industry facilities, varies depending on which of the Convention's three schedules the chemicals being produced-in the case of Schedule 2, produced, processed or consumed - appear on. Facilities producing Schedule 1 chemicals, for example, are subjected to inspection at a rate ranging from once to twice per year. Currently, only 27 such facilities are under verification, and most of these are laboratories with the capacity to produce only gram quantities of Schedule 1 chemicals. The majority have produced less than $100 \mathrm{~g}$ of Schedule 1 chemicals during the last 5 years. For the approximately 150 Schedule 2 plant sites subject to inspection, the inspection frequency is determined by the assessed potential risk posed by the chemicals and the capabilities of the facility producing, processing, or consuming them. It is anticipated that the majority of Schedule 2 plant sites may receive up to 3 inspections over a period of 10 years. A small number of plant sites, those judged to pose a more significant risk to the object and purpose of the Convention, will receive more frequent inspections. The duration of each inspection is limited to $96 \mathrm{~h}$. Approximately 400 sites are currently subject to inspection under Schedule 3. Individual sites are selected for inspection on the basis of agreed weighting factors using a specially developed computer program. For Schedule 3 facilities, the inspection duration is limited to $24 \mathrm{~h}$. The inspection regime for DOCs/PSFs is somewhat different from the other Article XI inspections in that the focus of the inspection is on the capability of the plant rather than on the chemicals. The primary aim is to confirm that the plant is not being used, and has not been used, to produce Schedule 1 chemicals. Sites are selected for inspection from the list of approximately 4000 declared sites using a similar process to that used for the selection of Schedule 3 facilities. Once again, the duration of each inspection is limited to $24 \mathrm{~h}$.

In addition to these routine inspections, the Technical Secretariat may also be required to undertake two other types of inspection, namely, an investigation of alleged use and a challenge inspection. The former would occur in situations where a State Party believed that it had either been subjected to an attack by chemical weapons or was under the threat of such an attack. The latter can be instigated at the request of any State Party that believes it has evidence that another State Party is undertaking activities that are not in compliance with the Convention. A challenge inspection can be requested at any time and can involve any location on the territory of the challenged State Party. To date, the Technical Secretariat has not been required to undertake either a challenge inspection or an investigation of alleged use. 


\section{ROLE OF CHEMICAL ANALYSIS}

The role of chemical analysis during inspections is worthy of particular mention. During the negotiation of the CWC, the use of sampling followed by either on-site or off-site chemical analysis was seen as being an important component of the Convention's verification regime. After five years and more than 1000 inspections, the use of sampling and chemical analysis has, however, proved to be the rare exception rather than the norm. In fact, only at chemical weapons destruction sites are sampling and analysis used on a routine basis by inspection teams. One reason for this low requirement for sampling and analysis is that there have been no challenge inspections or investigations of alleged use. Both of these types of inspection would be expected to rely heavily on the use of sampling and analysis.

It was also anticipated, however, that sampling and analysis would be regularly used during chemical industry inspections. Why has this not happened? The answer is of course complex, but a key contributing factor is that the inspection team's principal approved analytical tool is gas chromatography coupled with mass spectrometry (GC/MS). This equipment poses a number of problems, not least of which is that along with the necessary supporting equipment it can weigh in at between 300 and $500 \mathrm{~kg}$ with a bulk of around one cubic metre. Inspection teams routinely travel on scheduled passenger airlines to the point of entry and often by internal scheduled airlines to the actual inspection site. Transporting this volume of equipment over such routes is not only extremely expensive, but, more often than not, also poses severe logistical problems.

This factor alone, however, would not have deterred the inspection teams from taking the analytical equipment. A major problem is that GC/MS is often viewed as being a far too intrusive technique; a full-spectrum analysis of a sample taken at a chemical industry site, for example, will also reveal information that is not relevant to the Convention and, more importantly, may have a high commercial value. Many chemical industry companies, therefore, have serious concerns about the routine use of sampling and analysis during inspections of their sites. In their view, sampling and analysis should be a means of last resort and only used where necessary to resolve any anomaly, which has arisen during an inspection. The problem with this approach is that the inspection teams would need to carry their analytical equipment to all industry inspections, but only use it on rare occasions. For the reasons already given, this is not a practical option. It follows, therefore, that if the Organization wishes to maintain the option for inspection teams to routinely use sampling and analysis during inspections, an alternative solution to this problem needs to be found.

The Convention also makes provision, under certain conditions, for samples taken during an inspection to be sent off-site for analysis at two or more specialist laboratories designated by the Organisation [3,4]. Although the OPCW currently has 16 designated laboratories, these are located in only 3 of its 5 geographic regions. At present, there are no qualifying laboratories in either the African or Latin American and Caribbean regions. The procedures drafted by the Technical Secretariat for the collection, handling, transport, and analysis of samples [5] have also not yet been formally approved by the States Parties. In addition, despite the fact that the transport of samples in support of the Convention is provided for under the International Air Transport Association (IATA) dangerous goods regulations [6], most airlines remain reluctant to accept such samples for air transport. Given all of these factors, it is not clear that, at the present time, the use of off-site analysis is a viable option.

\section{CONCLUSION}

Despite its complexity, the Convention's verification regime has been successfully implemented. A number of problems, however, remain to be resolved. The forthcoming Review Conference, in 2003, will provide an ideal opportunity for the States Parties to revisit these problems and, where practicable, reach agreement on a means for their final resolution. 


\section{REFERENCES}

1. CWC. The Convention on the Prohibition of the Development, Production, Stockpiling and Use of Chemical Weapons and on their Destruction, 32 I.L.M. 800, 13 January 1993. Available at $<$ www.OPCW.org $>$.

2. CWC. Annex on Chemicals.

3. CWC. Verification Annex, Part II, para. 55.

4. OPCW. The Legal Texts. L. W. Tabassi (Ed.), pp. 193-202, T. M. C. Asser. Press, The Hague, The Netherlands (1999).

5. CWC.Verification Annex, Part II, para. 56.

6. Dangerous Goods Regulations, $43^{\text {rd }}$ ed., International Air Transport Association, January 2002. Available at $<$ www.IATA.org/cargo/dg $>$. 